\title{
Bone quality and osteoporosis therapy
}

\author{
Qualidade óssea e tratamento da osteoporose
}

Regina Matsunaga Martin', Pedro Henrique S. Correa'

\section{SUMMARY}

${ }^{1}$ Unidade de Doenças Osteometabólicas, Hospital das Clínicas, Faculdade de Medicina, Universidade de São Paulo (HC-FMUSP), São Paulo, SP, Brasi
Correspondence to: Pedro Henrique S. Correa Hospital das Clínicas,

Faculdade de Medicina, Universidade de São Paulo Av. Enéas Carvalho Aguiar, 155, 8o andar, bloco 3

05403-900 - São Paulo, SP, Brasil correaph@uol.com.br

Received on Jan/19/2010 Accepted on Feb/28/2010
Although BMD measured by DXA is a useful clinical tool for osteoporosis diagnosis, changes resulting from osteoporosis treatment only partially explain the observed reduction in fractures. Several other bone properties that influence its resistance to fractures and explain this discrepancy have been defined as "bone quality". Bone quality is determined by its structural and material properties and orchestrated by bone turnover, a continuous process of renewal through which old or damaged bone is replaced by a mechanically healthy bone and calcium homeostasis is maintained. Bone structural properties include its geometry (size and shape) and microarchitecture (trabecular architecture and cortical porosity), while bone material properties include its mineral and collagen composition as well as microdamage and its repair. This review aims to update concepts surrounding bone quality and how drugs employed to treat osteoporosis might influence them. Arq Bras Endocrinol Metab. 2010;54(2):186-99

Keywords

Bone quality; turnover; strength; fracture; osteoporosis; treatment

\section{SUMÁRIO}

Embora a DMO, medida por DEXA, seja um recurso clínico útil para o diagnóstico da osteoporose, mudanças resultantes do tratamento da osteoporose explicam apenas parcialmente a redução de fraturas. As demais propriedades ósseas que influenciam sua resistência a fraturas, que não se referem à massa óssea e explicam a discrepância entre os valores de DMO e o risco de fratura, têm sido definidas como "qualidade óssea". A qualidade óssea é determinada por suas propriedades estruturais e materiais e orquestrada pela remodelação óssea, um processo contínuo de renovação por meio do qual o osso velho ou danificado é substituído por um osso mecanicamente saudável e a homeostase do cálcio é mantida. As propriedades estruturais ósseas incluem suas geometria (tamanho e formato) e microarquitetura (arquitetura trabecular e porosidade cortical), enquanto as propriedades materiais referem-se à sua composição mineral e colágena assim como ao microdano e seu reparo. 0 objetivo desta revisão é uma atualização sobre qualidade óssea e como os medicamentos empregados no tratamento da osteoporose podem modificá-la. Arq Bras Endocrinol Metab. 2010;54(2):186-99

\section{Descritores}

Qualidade óssea; remodelação; força; fratura; osteoporose; tratamento

\section{INTRODUCTION}

$\mathrm{O}$ steoporosis is a bone disease characterized by low bone strength leading to increasing susceptibility to bone fracture. The capacity of bone to resist mechanical forces and fractures depends not only on the quantity of bone tissue but also on its quality.

The amount of bone tissue is in part evaluated by measuring bone mineral density (BMD) using dual X- ray absorptiometry (DXA). BMD is currently the most important determinant of bone strength and fracture risk (1), nevertheless it does not entirely predict the risk of fracture and changes in BMD account for only a portion of the fracture risk reduction observed with osteoporosis therapies. Older people can have up to tenfold increased 10-year fracture risk in comparison with younger individuals with the same BMD (2). Thus, in 
individuals with comparable $\mathrm{BMD}$, fracture risks are not the same. In addition, more than $50 \%$ of all fractures occur in women with osteopenia, as defined by a $-2.5<$ BMD T score $\leq-1$; at-risk women in this group will not be detected by applying the World Health Organization BMD definition of osteoporosis (3).

Changes in BMD associated with antiresorptive treatments account for less than $40 \%$ of its effect in reducing vertebral fracture risk $(4,5)$ demonstrating that changes in BMD with osteoporosis treatments only partially explain fracture risk reduction and that additional independent factors may contribute to the clinical efficacy of these therapies.

The term "bone quality" was therefore introduced to refer to the combination of factors that influence fracture risk but are not related to bone mass $(6,7)$.

\section{BONE QUALITY}

Bone quality is determined by structural and material properties that are influenced by bone turnover rate. Bone turnover or remodeling is a continuous process of bone renewal in which old or damaged bone is resorbed and new bone is formed to replace it producing a mechanically sound bone and maintaining calcium homeostasis. Bone structural properties include its geometry (size and shape) and microarchitecture (trabecular/cancellous architecture and cortical thickness/ porosity), while bone material properties include its mineral and collagen composition as well as microdamage and its repair (Figure 1).

While there is no precise measure of bone strength, BMD has been widely used as a noninvasive surrogate of this parameter as well as an accurate predictor of fracture risk. Besides using DXA, BMD can be measured by quantitative computer tomography (QCT) reflect-

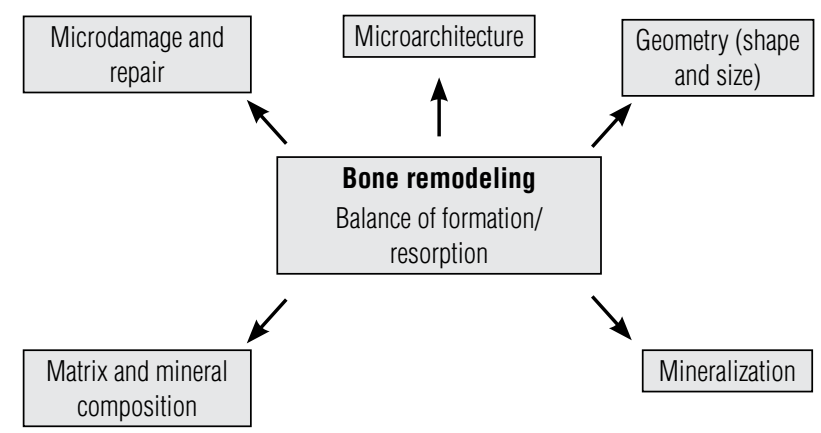

Figure 1. Determinants of bone quality. ing volumetric BMD instead of an areal projection and therefore allowing the determination of the actual volumetric density of bone independent of its size.

However, using bone biopsy or autopsy specimens, a number of approaches have been developed providing better comprehension of how bone quality contributes to bone strength in untreated and treated disease states. The most popular of these approaches is histomorphometry, but newer imaging techniques such as microcomputed tomography $(\mu \mathrm{CT})$ and magnetic resonance microimaging ( $\mu \mathrm{MRI})$ allow the measurement of three-dimensional (3D) trabecular microarchitecture in bone specimens in a non-destructive way. Although MRI and $\mu \mathrm{CT}$ analysis are reliable, they should be preferably used in combination to obtain valid conclusions. Nevertheless, the use of these techniques is still restricted due to their limited availability, high cost and relatively high radiation exposure.

\section{Bone turnover or remodeling}

Bone turnover coordinates the various factors that contribute to bone quality (Figure 1). The balance between bone resorption and formation is the key component in preserving bone quality, repairing microarchitectural damage, maintaining BMD and reducing fracture risk.

Accelerated bone turnover leads to the irreversible loss of some trabeculae, resulting in weaker bone and increased fracture risk. Since it is not possible to routinely assess trabecular connectivity in patients with osteoporosis, bone turnover is most commonly assessed in clinical practice by the measurement of biochemical markers of bone turnover.

Detectable in blood or urine, bone turnover markers are products of osteoblasts/osteocytes and osteoclasts type I collagen breakdown reflecting bone formation and bone resorption, respectively. For instance, CTx (bone type I collagen C-telopeptide) is a product of collagen degradation and therefore mirrors bone resorption; elevated CTx levels generally mean accelerated bone turnover.

Bone markers are also helpful for assessing response to antiresorptive therapy; they are commonly reduced after one (resorption markers) to four (formation markers) months of treatment. However, there is considerable intra- and inter-individual variability, and levels may be affected by diet and the circadian rhythm. Nevertheless, the measurement of bone turnover markers in addition to BMD has been proposed as a more effective surrogate for predicting fracture risk than BMD alone (8). 
Bone turnover can also be assessed by bone histomorphometry using tetracycline labeling prior to biopsy. The extent of tetracycline-labeled surfaces indicates bone turnover, provided that bone remodeling is in a steady state and that bone resorption and formation are coupled.

Histomorphometry consists of the quantitative analysis of bone resorption parameters, formation and structure on histological sections, and is largely considered the gold standard for assessing bone turnover since it is the only available method for direct in situ analysis of bone cells and their activity. In addition, this technique can assess 2D bone microarchitecture allowing measurements such as thickness and connectivity of trabeculae. Moreover, computerized analysis of biopsy specimens can assess resorption cavity characteristics in quantitative terms such as mean and maximum eroded depth, and eroded area. Nevertheless, bone turnover in iliac crest biopsies may not reflect changes at other skeletal sites and the invasive nature of this procedure may pose as a disadvantage to its widespread use (6).

Biochemical markers and histomorphometry differ in their assessment of bone turnover particularly in respect to the degree of suppression of bone turnover by anti-resorptive agents, which is generally greater when assessed by the latter technique.

\section{Bone geometry}

The external diameter and cortical thickness of bone play crucial roles in determining bone strength. Bone geometry takes into account the distribution of bone mass and the ability of bone to resist torsion and bending (i.e., the wider the external diameter of a cylinder, the higher its resistance to bending). Therefore, for the same areal BMD, a wider bone has greater bending strength and axial strength because its mass is distributed further away from the center (Figure 2A).

Considerable evidence indicates that age-related declines in the material properties of bone tissue are accompanied by a redistribution of cortical and trabecular bone. Specifically in the appendicular skeleton these changes involve endosteal resorption within the bone combined with periosteal apposition on the external surface. This leads to an age-related increase in the diameter of long bones but a decrease in cortical thickness. This increase in the outer diameter helps to maintain the resistance to bending and torsional loads. For many years, it has been suggested that men undergo this pattern of favorable geometric adaptation to a greater extent than women, providing one possible explanation for lower fracture rates in elderly men than women. However, recent data has shown that both men and women undergo favorable geometric changes with aging (Figure $2 \mathrm{~B}$ ).
A

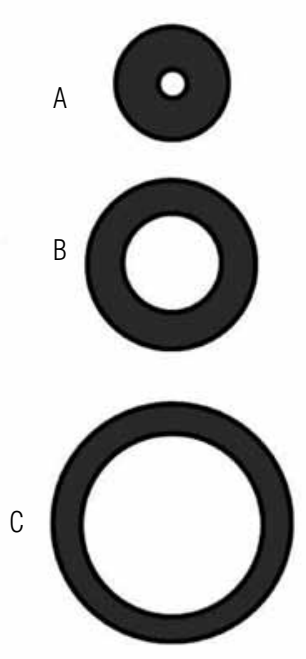

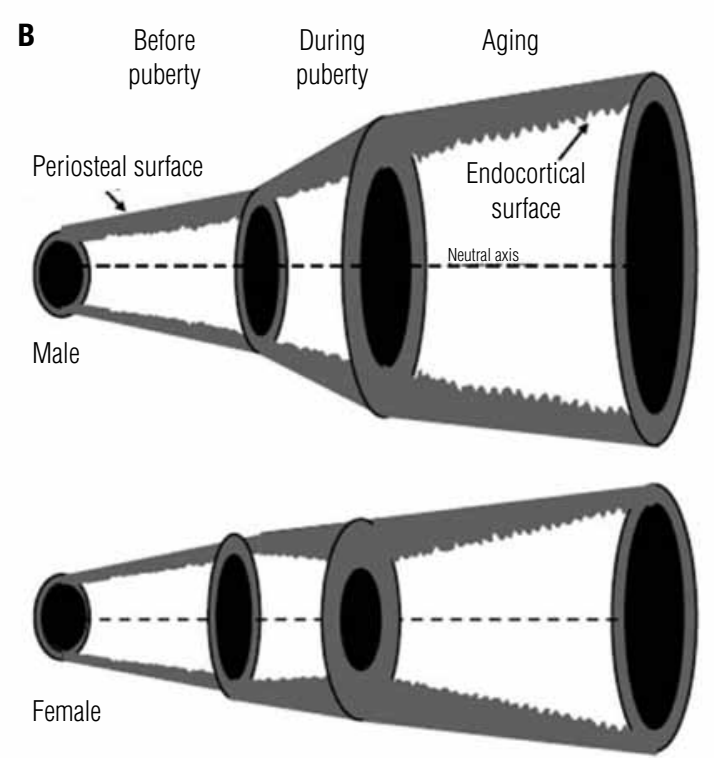

Figure 2. Influence of bone geometry on bone strength. $A$. for the same areal BMD, bone $C$ has progressively greater bending strength and axial strength than bone $B$ and bone $A$ because the mass of bone $C$ is distributed further away from the center - adapted from Bouxsein (63). B. Sex and aging differences in periosteal apposition and endocortical resorption in tubular bones. Adapted from Seeman (64). 


\section{Bone microarchitecture}

Changes in bone microarchitecture make an important contribution to bone strength that may not always be captured by bone mineral density measurements. Cortical and cancellous architecture are both important in this respect. In cancellous bone, the number and thickness of trabeculae and their connectivity and orientation (anisotropy) contribute to bone strength, whilst in cortical bone its width and porosity are the main determinants.

Altered bone microarchitecture in untreated and treated disease states result from underlying changes in bone remodeling. High turnover states and increased osteoclast activity predispose to trabecular penetration, loss of connectivity, cortical thinning and increased cortical porosity, whereas low bone turnover states and reduced bone formation are associated with trabecular thinning and relative preservation of bone micro architecture.

Although some of these architectural features can be assessed by bone histomorphometry, more sophisticated methods have now been developed that enable $3 \mathrm{D}$ visualization and quantification.

The development of $\mu \mathrm{CT}$ scanning has enabled 3D evaluation of trabecular bone specimens at resolutions of 14-50 $\mu \mathrm{m}$. With the use of $\mu \mathrm{CT}$, bone volume (BV), trabecular number and thickness, and connectivity can be assessed. Strain on bone tissue can be measured by comparing structural elements with and without mechanical load. This technique is also potentially useful for studying molecular aspects of bone physiology as it can be performed at low temperatures, preserving RNA and therefore allowing the investigation of interactions between genetic profiles and biomechanical properties (6).

Microfinite element analysis by combining bone geometry with material characteristics to predict bone strength is a promising technique for fracture assessment based on the calculation of the mechanical properties of trabecular sites from high-resolution images. The combined use of these two methods provided an in vivo assessment of apparent $\mathrm{BV}$ to total volume (BV/ $\mathrm{TV}$ ) and quantified changes in horizontal elements of trabecular bone of the distal radius in postmenopausal women in terms of both structure and strength (6).

Finally, noninvasive, nonionizing high-resolution MRI can be used to evaluate trabecular bone. It has been employed to compare the trabecular structure of the calcaneus in women with and without hip fractures related to osteoporosis, allowing clear distinction between the two groups (9). More recently, the effects of calcitonin on parameters of trabecular microarchitecture were analyzed comparing both noninvasive MRI at multiple skeletal sites (radius, hip and calcaneous) and $\mu \mathrm{CT}$ / histomorphometry acquired by iliac crest bone biopsy, in the QUEST (Qualitative Effects of Salmon-Calcitonin Treatment) trial. Although the results supported the use of MRI for assessment of trabecular microarchitecture in clinical research trials, the authors have highlighted sitespecific differences in response to antiresorptive therapies and the need for sufficiently large sampling in order to reliably assess bone architecture (10).

\section{Bone matrix composition}

Bone matrix has essentially two constituents, mineral and collagen. The majority of evidence suggests that in normal bone the mineral provides stiffness and strength whereas collagen affords bone its ductility and ability to absorb energy (toughness) before fracturing.

Bone collagen is continuously renewed and its fibers are stabilized posttranslationally through enzymatic cross-linking (pyridinoline and deoxypyridinoline), non-enzymatic glycation generating AGEs (aged glycation product ends) such as pentosidine, and $\beta$-isomerization of the CTx epitope.

The ratio of pyridinoline/deoxypyridinoline (PYD/ DPD) has been shown to be positively associated with strength and stiffness in bone, but appears to have little correlation with toughness. Non-enzymatic collagen cross-links (AGEs) make the tissue more brittle and susceptible to fractures. In vitro studies of fetal bovine cortical bone have recently shown that changes in cross-link (PYD, DPD and AGEs) and in the degree of $\beta$-isomerization of carboxy telopeptide of type I collagen accompany changes in bone mechanical properties resultant from aging (11).

The excess of AGEs leads to a decrease in toughness and strength due to increased stiffness. Moreover, AGE-receptors present on certain cells (osteoblasts, for instance) may downregulate these cells. Interestingly, AGEs are increased in diabetes and may participate in the accelerated aging experienced by diabetic subjects (12).

CTx originates from recently synthesized type I collagen as $\alpha \alpha \mathrm{CTx}$ and undergoes isomerization generating $\beta \beta C T x$, which is released from aged type I collagen. Therefore, the assessment of $\alpha \alpha$ and $\beta \beta$ CTx fragments by enzyme-linked immunosorbent assay reflects the age of endogenous bone collagen. The calculated $\alpha \alpha / \beta \beta$ CTx ratio in urine samples reflects mean bone collagen age and can be used as an index of bone matrix quality (13) (Figure 3 ). In agreement with this concept, it 


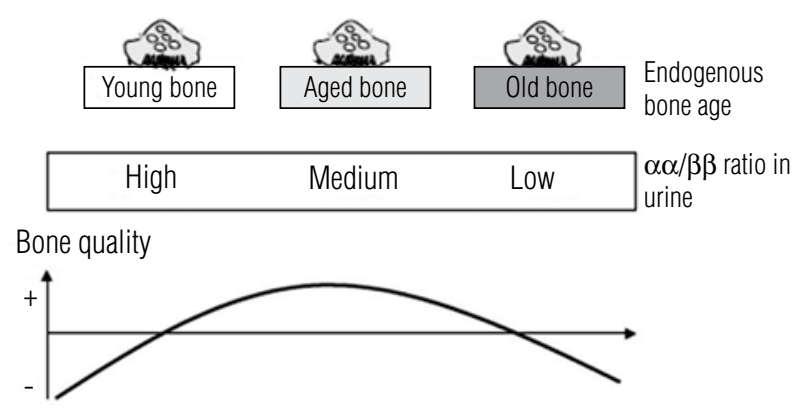

Figure 3. Schematic overview of the bone collagen age profile measured as the ratio between $\alpha \alpha C T x$ and $\beta \beta C T x$. Adapted from Leeming and cols. (13).

has been shown that the mean age of bone assessed by $\alpha \alpha / \beta \beta$ CTx is higher in accelerated bone turnover (trabecular bone) and conversely lower in reduced bone turnover (cortical bone).

\section{Mineralization}

Mineralization of bone matrix consists of two successive steps. Primary mineralization occurs when the new collagen matrix begins to mineralize quickly and represents $50 \%$ to $60 \%$ of the mineralization maximum. Subsequently, the rate of mineralization slows down and secondary mineralization proceeds for a number of years. Typically, mineralization stabilizes around $90 \%$ to $95 \%$ of maximum. The degree of secondary mineralization is dependent on bone turnover; when this is low, there is more time for mineralization to proceed whereas in high turnover states, recently formed bone is removed before there is time for appropriate secondary mineralization.

As mineralization increases, the tissue becomes more brittle and requires less energy to fracture. Therefore, it is possible for a bone that is hypermineralized to be more fragile than a bone with a lower degree of mineralization. This effect may partially explain the findings of Riggs and cols. (14), who demonstrated that despite dramatic increases in BMD with fluoride treatment there was a significant increase in the number of patients with nonvertebral fractures in the fluoride group as compared with placebo. Conversely, when bone resorption begins before completion of mineralization, a cumulative deficit in mineralization arises leading to decreased bone stiffness and strength.

The degree of mineralization and its distribution throughout bone can be measured ex vivo by several methods including microradiography, quantitative back-scattered electron imaging (qBEI) and spectro- scopic techniques. The degree of mineralization is captured by BMD measurements but its contribution, in relation to other factors influencing $\mathrm{BMD}$, cannot be directly deduced.

\section{Microdamage}

Bone undergoes repeated cyclic loading and the resulting fatigue damage in bone matrix is expressed through microcracks or microdamage. Microdamage is generally defined as linear cracks detectable by light microscopy, and although the optimal method to quantify microdamage in bone is under debate, numerous studies have now shown that the accumulation of damage weakens the bone. Moreover, it appears that microdamage triggers remodeling, presumably to repair the damaged tissue (15). On the other hand, accumulation of microdamage may result from increased mineralization secondary to suppression of remodeling, making the bone more brittle.

There is ongoing debate regarding the optimal level of bone turnover to prevent architectural deterioration while preserving the ability of bone to maintain calcium homeostasis, respond to altered mechanical loading, and to repair microdamage. The role of microdamage in age-related fragility fractures has yet to be established. Microdamage accumulation has been proposed to be a factor that may contribute to increased skeletal fragility with age (16).

Techniques to detect microcracks require expensive technologies and training. Most data have been obtained in animal models, and the applicability of some experimental results to the humans remains unclear. Studying microdamage in humans, specifically to determine the impact of bone drugs, relies on iliac crest bone biopsies, which may not be appropriate because of the low numerical crack density on this site in comparison to others. Noninvasive techniques need to be developed to improve assessment of microdamage in vivo (17).

\section{EFFECTS OF OSTEOPOROSIS MEDICATIONS ON BONE QUALITY}

Drugs for osteoporosis treatment can be classified in two groups: antiresorptive or stimulating of bone formation. However, it is increasingly clear that they act not only by improving BMD but also by increasing bone strength, modifying bone quality, and therefore reducing the risk of fracture. 


\section{Bisphosphonates (BPs)}

Bisphosphonates (BPs) have great affinity for bone mineral and inhibitory effects on osteoclasts. The attachment of BPs to crystalline hydroxyapatite is determined by their structure, mainly the $\mathrm{P}-\mathrm{C}-\mathrm{P}$ configuration. $\mathrm{Ni}$ trogen-containing bisphosphonates have become the standard of care for osteoporosis. Current oral BPs are: alendronate (daily or weekly dosing), risedronate (daily or weekly dosing) and ibandronate (monthly dosing) whereas intravenous regimens are available with pamidronate and zoledronic acid (quarterly or yearly) (18).

Besides significantly increase BMD in patients with osteoporosis, BPs also act by modifying bone quality to improve bone strength. Although it is difficult to assess the actions of BPs on bone quality in general practice, evidence in that direction has accumulated in recent years.

\section{Effects on bone mineralization}

BPs decrease bone turnover and increase the duration of the secondary mineralization, thus improving the degree of mineralization. Boivin and cols. (19), treating postmenopausal women with osteoporosis with threeyear alendronate therapy, have shown an increase in mean mineralization at the iliac bone of approximately $11 \%$ both in cancellous and cortical bone. Further, Borah and cols. (20), using $\mu \mathrm{CT}$ to assess biopsies from patients at baseline and after 3 and 5 years of risedronate therapy, showed an increased homogeneity of mineralization. There was no significant difference in average or homogeneity mineralization values between 3 and 5 years of risedronate therapy, neither hypermineralization of the bone matrix was observed (21). Moreover, Recker and cols. (22) have shown that annual IV administration of zoledronic acid during three years is effective in reducing bone remodeling and preserving bone structure in postmenopausal women with osteoporosis. However, differences between zoledronic acid and oral BPs on mineralization have been verified as highlighted by Ebeling and Burr (23): zoledronic acid stimulates osteoblast activity resulting in accelerated mineral apposition and increases bone volume but not secondary mineralization.

\section{Role in microdamage}

Bone remodeling aims to repair fatigue microdamage, nevertheless an excessive reduction of bone turnover may result in inadequate microdamage repair leading to a fracture. Animal bones overtreated with BPs exhibit suppressed trabecular bone turnover associated with increased vertebral strength, even with significant microdamage accumulation and reduced intrinsic energy absorption capacity (toughness) (24,25).

The mechanism of bisphosphonate-induced microdamage accumulation has not been fully established. BPs suppress turnover, reducing both targeted and stochastic remodeling, and allowing microdamage to persist for longer in comparison to untreated bone. More, increased mineralization and increased tissue homogeneity, both of which resultant from BP treatment, are permissive to the formation and accumulation of microdamage (26).

\section{Action on type I collagen}

Limited data is available concerning BP effects on the organic component of bone.

Saito and cols. (27) and Allen and cols. (28) have documented changes in enzymatic (PYD/DPD), nonenzymatic cross-linking (AGEs) and collagen isomerization of the organic matrix in bisphosphonate-treated animals. Following treatment with a wide range of BP doses, the ratio PYD/DPD in the trabecular bone of lumbar vertebrae was significantly increased compared to vehicle-treated animals as well as the level of pentosidine (AGEs) in a dose-dependent fashion; conversely, the ratio of $\alpha \alpha / \beta \beta$ CTx was decreased when compared to untreated animals.

In human bone, pentosidine markedly increases with age, and its content in bone from patients with hip fracture is significantly higher than that of non-fractured age-matched controls (29).

As the organic matrix is known to contribute to biomechanical properties, these data suggest that changes in the non-mineral component with BP treatment may influence mechanical properties and therefore fracture risk. However, changes in the organic matrix may have some effect on tissue strength and stiffness, even if these properties are predominantly determined by mineralization.

\section{Effects on bone geometry and microarchitecture}

Each of the changes obtained with BPs treatment has a significant effect on material-level biomechanical properties, independent of changes in bone mass, but their specific individual contribution is difficult to assess experimentally. Probably, effects on bone mineralization and collagen cross-linking tend to increase bone stiff- 
ness and strength, whereas the increased microdamage tends to decrease both. The relevance of these changes remains enigmatic, however, considering that BPs also modify bone geometry and microarchitecture.

In this way, Davison and cols. (30) reviewed reports of reduced cortical porosity following treatment with $\mathrm{BP}$ and changes in parameters of trabecular 3D architecture after one-year risedronate therapy assessed by $\mu \mathrm{CT}$. In the placebo group, bone volume, trabecular number and trabecular connectivity decreased whereas no such deterioration was observed in the risedronate group, with similar results even after 3 years of risedronate therapy.

In the DIVA (Dosing IntraVenous Administration) study, conducted in postmenopausal women, around $12 \mathrm{mg}$ in a year of IV ibandronate provided significantly greater gains in BMD than $2.5 \mathrm{mg}$ daily oral ibandronate, with equivalent efficacy and similar safety. Following 2 years of ibandronate treatment, trabecular bone maintained its normal lamellar structure with no evidence of woven bone, marrow fibrosis, cellular toxicity, or other qualitative abnormalities. Histomorphometric analysis of 89 transiliac bone biopsies demonstrated normal micro-structure of newly formed bone with normal mineralization and reduced remodeling after oral or IV ibandronate (31). Because the IV ibandronate regimen in DIVA has an annual cumulative exposure similar to the $150 \mathrm{mg}$ monthly oral ibandronate, it is possible that the positive histomorphometric and bone safety profiles observed may also reflect the effects of its current oral use.

To date, it appears these macro-level changes drive the anti-fracture efficacy of BPs, and can adequately compensate for reduced material properties. Nevertheless, research on long-term BP treatment is certainly warranted since structural-level benefits of BPs could potentially be overridden with time (26).

\section{Recombinant human parathyroid hormone peptide 1-34: teriparatide (TPT)}

The effects of PTH on the skeleton are complex and differ between states of elevated endogenous and exogenous administration of PTH.

The amino-terminal fragment of human parathyroid hormone (PTH 1-34), also known as teriparatide (recombinant DNA origin), has an anabolic effect on bone if administrated intermittently serving as a bone-forming agent for the treatment of osteoporosis.
A daily subcutaneous injection of teriparatide (TPT) produces a rapid increase in markers of bone formation, followed by a more delayed increase in markers of bone resorption. It also significantly increases BMD measured by DXA reducing the risk of new vertebral and nonvertebral fractures by $65 \%$ and $53 \%$, respectively, in postmenopausal women with osteoporosis. That increase in BMD accounts for no more than $40 \%$ of its anti-fracture efficacy, suggesting that TPT can also modify bone quality (32).

Improvement in both trabecular and cortical bone microarchitecture has been suggested in patients using TPT. To elucidate these issues, investigations have been conducted to evaluate whether changes in BMD correlate with bone structural improvements observed in patients treated with TPT.

\section{Bone turnover}

Assessment with bone histomorphometry (33) has shown that TPT changes bone remodeling by increasing bone formation rates and turnover, securing a large number of active bone multicellular units (BMUs) laying down new bone. Stimulation of bone remodeling by TPT at both cancellous and endosteal surface reaches a maximum after 6 months of treatment. Subsequently, bone turnover returns toward levels measured in untreated postmenopausal women, with formation still exceeding resorption. In addition, there is direct evidence that 12 to 24 -months TPT therapy induce modeling bone formation at quiescent surfaces (34). These mechanisms may contribute to the improvement of trabecular and cortical architecture seen after TPT treatment.

\section{Microarchitecture and geometry}

TPT treatment stimulates both trabecular and cortical bone formation, resulting in increased cancellous bone volume and cortical thickness (35). There is also some evidence for increased periosteal bone apposition, leading to a gain in bone size (36). Thus, to assess modifications on cortical bone of postmenopausal women with osteoporosis receiving TPT therapy, a cross-sectional study estimated parameters of cortical bone quality by peripheral QCT in their nondominant distal radius. Compared with placebo, patients under TPT had significantly higher total bone mineral content, total and cortical bone areas, periosteal and endocortical circumferences (37). 
However, cortical porosity in patients with hyperparathyroidism has raised the concern that intermittent PTH given to treat osteoporotic patients may weaken cortical bone by increasing its porosity. To evaluate this potential effect of TPT therapy, Burr and cols. (38) treated ovariectomized monkeys for up to 18 months with TPT and observed increased dose-dependent intracortical porosity in their humerus without a significant effect on bone strength. Most porosity was concentrated near the endocortical surface where its mechanical effect is small. Further, Sato and cols. (39) conducted a detailed quantitative analysis of the effects of TPT on the proximal femur of ovariectomized monkeys and concluded that TPT had beneficial effects on the proximal femur despite increasing cortical porosity. Cortical porosity did not adversely affect the mechanical integrity of the proximal femur because enhanced cortical area (probably due to increased periosteal bone apposition) and trabecular bone volume more than compensated for the porosity. Of note, much of the beneficial effects of TPT were retained 6 months after treatment.

\section{Mineralization}

Misof and cols. (40) have evaluated BMD distribution of iliac crest bone biopsies before and after TPT treatment for 18-36 months in men and women with osteoporosis using qBEI. In cortical bone, pairwise comparison of biopsies before and after treatment revealed a reduction in the typical calcium concentration in men but no change in women, with an increase in the heterogeneity of mineralization in both. In cancellous bone, there was no change in the typical calcium concentration, but there was a greater heterogeneity of mineralization in both men and women due to newly formed bone matrix. Small angle X-ray scattering performed on a subgroup of subjects revealed normal collagen/mineral structure. These findings confirm the observations that PTH stimulates skeletal remodeling, resulting in an increased percentage of newly formed bone matrix of lower mineral density.

\section{Collagen and microdamage}

Garnero and cols. (41) have studied the effects of PTH (1-84) and alendronate (ALN) on urinary $\alpha \alpha / \beta \beta$ CTx ratio in postmenopausal women with osteoporosis. During the first year, there was no significant change in the $\alpha \alpha / \beta \beta$ CTx ratio with PTH or ALN treatment, suggesting that type I collagen degradation products excreted in the urine during the first year of PTH may arise predominantly from resting bone that was formed before initiating therapy. Alternatively, isomerization of collagen formed during PTH treatment reached equilibrium before being degraded. At 24 months, however, there was a marked increase in the $\alpha \alpha / \beta \beta$ CTx ratio in women who had received PTH during the first year followed by a second year of placebo or ALN whereas the ratio only slightly increased after 2 yr of continuous ALN, suggesting that PTH therapy may result in decreased bone collagen maturation. The authors conclude that treatment with PTH (1-84) for $1 \mathrm{yr}$ followed by $1 \mathrm{yr}$ of placebo or ALN may be associated with decreased type I collagen isomerization. The influence of these biochemical changes of type I collagen on bone fracture resistance remains to be studied.

Analogous results were obtained previously by Paschalis and cols. (42) analyzing bone biopsies from patients following placebo or TPT. In the TPT group, a trend towards an increase in divalent crosslinks was observed after treatment, corresponding to increased formation of newly synthesized collagen.

Suppression of bone turnover by BPs is associated with increased bone microdamage accumulation in animal models but effects of TPT on microdamage accumulation had not been reported. Hence Dobnig and cols. (43) have studied the effect of increased bone turnover and improved bone structure on microdamage accumulation in 66 postmenopausal women with osteoporosis who started with TPT $(20 \mu \mathrm{g} / \mathrm{d})$ as first treatment (38 women) and in those who switched from long-term ALN ( $10 \mathrm{mg} / \mathrm{d}$ or $70 \mathrm{mg} / \mathrm{wk}$ ) to TPT treatment ( 28 women). Iliac crest bone biopsies were collected and analyzed for microstructure and microdamage accumulation at baseline and after 24 months of TPT administration.

TPT treatment reduced microdamage accumulation in osteoporotic patients who had been previously treated with ALN and reduced crack length regardless of prior treatment. Moreover the authors highlighted that an intact microarchitecture is essential for maintaining microdamage accumulation at physiologically normal levels in osteoporotic patients.

\section{Strontium ranelate (SR)}

Strontium ranelate (SR) is an oral antiosteoporotic drug that promotes bone formation in vitro by enhancing pre-osteoblastic cell replication, increasing osteo- 
blastic differentiation and raising the osteoprotegerin/ RANK-L ratio. Aside from these effects on osteoblasts, SR decreases bone resorption by inhibiting osteoclast activity and osteoclastic differentiation (44). Recent studies have shown that the activation of osteoblast replication is partly mediated by the calcium sensing receptor $(\mathrm{CaR})$ which is also involved in the SR-induced osteoclast apoptosis (45).

Because strontium is a heavier element than calcium, its incorporation into bone influences BMD measurements. In addition, it has been shown that SR is distributed in calcified matrix and is easily exchangeable from bone mineral, being slightly linked to mature crystals through ionic substitution. The combined effects of strontium distribution in bone and increased X-ray absorption of strontium compared with calcium lead to amplification of BMD measurement by DXA. These effects account for approximately $50 \%$ of the measured changes in BMD. However, an algorithm for adjustment of BMD involves a number of assumptions and cannot be used for individual patients (46). Overall, BMD changes in patients treated with SR account for $75 \%$ of the reduction in fracture risk suggesting that this therapy also interferes on bone quality (45).

\section{Microarchitecture and geometry}

In vivo studies indicate that SR decreases bone resorption and promotes bone formation, preventing bone loss. This positive uncoupling between bone formation and resorption results in bone gain and improvements in bone geometry and microarchitecture in growing animals. When administered to female rats during 2 years, SR induced a dose-dependent increase in bone mechanical properties at the level of the vertebral body and midshaft femur (47). In addition, treatment with SR prevents the deleterious effect of ovariectomy on bone strength. After one year of exposure to SR, bone mechanical properties of vertebrae of ovariectomized rats were significantly preserved in association with a partial preservation of the trabecular microarchitecture: a dose-dependent effect on the bone volume/trabecular volume ratio and trabecular number and thickness (48).

Iliac crest bone biopsies of postmenopausal osteoporotic women analyzed by $3 \mathrm{D} \mu \mathrm{CT}$ have demonstrated some improvement of both trabecular and cortical bone microstructure after 3 years of treatment with SR. In comparison to placebo, patients treated with SR for 3 years showed significant increase in the number of trabeculae $(+14 \%)$, decrease of trabecular separation $(-16 \%)$ and increase in cortical thickness $(+18 \%)$. Furthermore, a significant decrease $(-22 \%)$ of the model index structure suggested a shift in trabecular structure from rodlike to plate-like configuration resulting in stronger bone. These changes in trabecular and cortical structure may explain the anti fracture efficacy of SR (49).

\section{Mineralization}

Boivin and cols. reported histomorphometric evaluation of osteoporotic women treated with SR and found no effect on crystal characteristics or mean degree of mineralization of bone (MDMB) over a large range of doses $(0.5,1$, and $2 \mathrm{~g} / \mathrm{d})(30)$.

\section{Estrogens: hormonal replacement therapy (HRT)}

The Women's Health Initiative (WHI) demonstrated the effect of hormone therapy on BMD and on osteoporotic fracture reduction at several sites, including the hip. Even though the benefits of postmenopausal hormone replacement therapy (HRT) on fracture were clear, adverse effects such as increased risk of stroke and deep vein thrombosis were concerning, aggravated by later findings of increased risk of breast cancer and lack of cardio-protective benefits (50). For these reasons, in spite of its effectiveness for preventing postmenopausal osteoporosis, HRT should only be considered in women at significant risk of osteoporosis who cannot take non-estrogenic medications.

\section{Bone turnover and microarchitecture}

HRT is an effective prophylactic treatment for early postmenopausal bone loss since it reduces bone remodeling, which may be accelerated by progressive osteoclastic hyperactivity. Besides, estrogens are also capable of exerting an anabolic effect in women with osteoporosis, even when started well into menopause as shown by Khastgir and cols. (51). Histomorphometric studies of iliac bone biopsies performed on 22 older postmenopausal females with low BMD, before and $6 \mathrm{yr}$ after HRT, revealed BMD improvement at both lumbar spine and proximal femur sites. Furthermore, they observed an increase in cancellous bone volume and an increment of wall thickness after $6 \mathrm{yr}$ of HRT, indicating net bone gain.

The investigation of estrogenic actions on the skeleton has mainly focused on cancellous bone. To investigate the effects of both conventional HRT and high-dose estradiol on cortical bone in postmenopausal 
women, Vedi and cols. (52) conducted histomorphometric studies plus image analysis of the iliac bone at baseline and $2 \mathrm{yr}$ after HRT. High-dose estrogen-treated women showed the highest cortical width while the proportion of canals with an eroded surface was significantly lower than in women before or after conventional HRT. Their bone formation rate was significantly lower than in untreated women and intermediate values were found in women treated with conventional HRT. These results provided evidence that estrogen induces suppression of bone turnover in iliac crest cortical bone of postmenopausal women, in a dose-dependent manner.

\section{Mineralization and collagen}

To assess whether HRT modifies the degree of bone mineralization and collagen cross-linking, Paschalis and cols. (53) analyzed bone samples from early postmenopausal women at baseline and 2 years after HRT by a combination of hystomorphometric and infrared imaging techniques. They observed a shift in the degree of bone mineralization and collagen cross-links ratio (PYD/DPD ratio) toward higher values after HRT, suggesting that the bone was more mature, as might be expected from suppressed osteoclastic activity.

\section{Selective estrogen receptor modulators (SERMs)}

During the past decade, considerable attention has been focused on SERMs as an alternative to postmenopausal estrogen therapy. These agents act as estrogen agonists in some tissues and antagonists in others due to their specific actions on estrogen receptors. Benefits with raloxifene (a nonsteroidal SERM) therapy arose from the MORE (Multiple Outcomes of Raloxifene Evaluation) trial, in which 7705 postmenopausal women with osteoporosis were studied. BMD increased in the spine and femoral neck and the risk of vertebral fractures was significantly reduced, without any significant effect on non-vertebral fractures. The risk of endometrial hyperplasia was unaltered and the risk of invasive breast cancer was significantly reduced while there was an increased risk of venous thromboembolism (54). Even though the risk of coronary events was unaltered by therapy, LDL cholesterol levels were reduced and HDL levels were raised.

Only $4 \%-5 \%$ of the fracture reduction observed with raloxifene (RLX) results from increments in lumbar spine or femoral neck BMD, suggesting that RLX may also improve bone matrix properties $(55)$.

\section{Bone turnover}

To compare raloxifene therapy to HRT, Weinstein and cols. (56) analyzed the impact of these drugs on bone turnover after one year of treatment. The frequency of remodeling events on cancellous bone and rate of bone formation in both cancellous and endocortical bone increased in the placebo group, while these measurements decreased in both drug treatment groups. BMD increased from baseline at the lumbar spine (in the HRT group) and in the total body (for both RLX and HRT). Compared with RLX group, the increase in BMD was greater in the HRT group at the lumbar spine but not in the total body. Bone markers significantly decreased in both active treatment groups, changes significantly different from those seen with placebo. Overall, the authors suggest that RLX preserves bone mass by reducing the elevated bone turnover found in postmenopausal women by mechanisms similar to those operative in postmenopausal women receiving HRT.

\section{Microarchitecture and geometry}

Although there are similarities between raloxifene and BPs in preventing decreases in maximal load, bone mass, and microarchitecture in ovariectomized rats, the raise in BMD is more pronounced after BP than RLX (57). This finding parallels observations from canine studies that showed a significant improvement of the mechanical properties at the material level after l-year treatment with raloxifene even if aBMD, vBMD, BV/ $\mathrm{TV}$, and percent ash remained unaltered in comparison with control. These material-level improvements have been detected at both cortical and trabecular bone sites.

In the clinical setting, a relatively mild effect of RLX on BMD has also been observed despite a very noteworthy vertebrae antifracture efficacy. The observed improvements in microarchitecture may, at least in part, underlie the ability of RLX to increase bone strength and reduce fracture risk, yet it seems that the substantial beneficial action on intrinsic bone material quality, both at the cortical and trabecular level, plays an important role in the mechanism by which this agent is effective in osteoporosis treatment. In addition, it should also be noted that SERMs are known to have a protective effect on osteocytes in vitro; however, there is no convincing evidence of this effect in humans (57).

\section{Mineralization}

The effects of RLX treatment $(60 \times 120 \mathrm{mg} / \mathrm{d})$ on mean degree of mineralization of bone (MDMB) were 
also investigated in a prospective longitudinal study of a subset of 64 patients enrolled in the MORE trial. Quantitative microradiography analysis of iliac crest biopsies taken at baseline and after 2 years of treatment revealed a significant dose-dependent increase on MDMB compared with baseline. The observed increase in mineral content with preserved heterogeneity of mineral distribution is a result of the ability of RLX to decrease bone turnover, therefore extending the duration of secondary mineralization of bone basic structural units (BSUs) and allowing new bone to achieve a higher degree of mineralization. This mechanism has been shown to improve the biomechanical properties of bone and should contribute to the reduction in fracture risk observed after treatment with RLX. On the other hand, increased skeletal mineral can improve structural rigidity and too much mineral may lead to an increase in brittleness (58).

\section{Collagen and microdamage}

It has been hypothesized that RLX may alter the organic matrix (26) and, in particular, collagen, which is known to contribute to the biomechanical and intrinsic properties of bone. To answer this question, Byrjalsen and cols. (11) evaluated the effect of different anti-resorptive treatments (BPs, HTR and RLX) on bone collagen maturation measured by the $\alpha \alpha / \beta \beta$ CTx ratio. It was found that these anti-resorptive therapies induce differences in the maturation profile of bone collagen, i. e. $\alpha \alpha / \beta \beta$ CTx ratio is greater after treatment with HRT than RLX whereas $\alpha \alpha / \beta \beta$ CTx ratio after RLX therapy is greater than BPs.

There is considerable debate on defining normal remodeling rate and the potential deleterious effects of an excessive suppression by antiresorptive agents, given the potential impairment on microdamage repair and on the replacement of old bone by fresh new units. Although no fracture data support this highly controversial theory, SERMs do not suppress bone turnover to an extent that would cause such concerns. In fact, the data show that RLX restores bone turnover to premenopausal levels (59) and experimental data demonstrate that the drug actually reduces microcrack density in bone tissue.

\section{Calcitonin (CTN)}

Calcitonin (CTN) is an endogenous polypeptide hormone secreted by thyroid $\mathrm{C}$ cells that inhibits bone resorption by osteoclasts. Nevertheless, there is also concern that prolonged exposure to CTN may downregulate calcitonin receptors on osteoclasts, which could allow the osteoclasts to recover from the suppressive action of CTN. Its intermittent administration has been recommended as a strategy to avoid clinical resistance $(60)$.

A number of randomized trials have suggested that injectable or intranasal salmon CTN is effective in prevention of trabecular bone loss in late menopause. One classical trial evaluated intranasal administration of 200 IU of calcitonin and showed a vertebral fracture reduction of $33-36 \%$ without substantial effects on BMD (61). A $30 \%$ reduction in hip fracture was observed by Kanis in patients treated with injectable CTN but data with usual doses of nasal CTN in nonvertebral sites are controversial. In addition, CTN may have an analgesic effect in women with acute vertebral fractures, which appears to be independent of its effect on osteoclastic resorption $(60)$.

Clinical studies addressing the effects of CTN on bone quality are scarce but at least one should be pointed out. The authors postulated that CTN therapy may be associated with improvements in bone microstructure that are not detected by BMD. To address this hypothesis, a 2-year randomized placebo-controlled study of daily dose of 200 IU salmon calcitonin nasal spray (CT-NS) was carried out including approximately 45 postmenopausal osteoporotic women per group, using the noninvasive MRI technology at multiple skeletal sites and $\mu \mathrm{CT} /$ histomorphometry from iliac crest bone biopsies to assess trabecular microarchitecture (10).

MRI assessment of distal radius and lower trochanter of the hip revealed preservation of parameters of trabecular microarchitecture in the CT-NS group, whereas significant deterioration was observed in the placebo group. Combined $\mu \mathrm{CT} /$ histomorphometric analysis of iliac crest bone biopsies as well as BMD measured by DXA did not reveal consistent differences in architecture between CT-NS and placebo groups.

In conclusion, the QUEST study results suggested therapeutic benefits of CT-NS in maintaining trabecular microarchitecture at multiple skeletal sites and supported the use of MRI technology in clinical research trials for assessing bone microstructure. Nevertheless, the results also highlighted site-specific differences in the response to antiresorptive therapies and the importance of sufficiently large sampling volumes to obtain reliable assessment of bone architecture (10). 


\section{SUMMARY AND CONCLUSIONS}

Despite genuine advance, therapy for osteoporosis still represents a considerable research challenge. BMD is a useful clinical tool for diagnosing and monitoring osteoporosis but has limitations that need to be recognized and addressed. Since drugs and bone disorders have a spectrum of effects ranging from the microscopic to the macroscopic level (Table 1) that may change depending on the underlying physiology of a particular patient and BMD may not detect all anticipated effects.

Bone turnover markers may be a useful complement for solving this puzzle as they reveal effects on bone remodeling in the absence of changes on bone density tests. Unfortunately, no monitoring technique is absolutely accurate. Future prospects for in vivo bone strength analysis using CT or MRI have yet to be developed to the point of clinical utility, but this may well be the way of the future. Finite element analyses can reproduce $3 \mathrm{D}$ constructs of bone through noninvasive measurements, congregating all elements of bone strength into a useful clinical tool for assessing therapeutic response $(62)$.

Up to now, the main effects of osteoporosis medications on bone quality can be summarized as follow. Antiresorptive therapy, specially the bisphosphonates, generally increases MDMB and homogeneity of mineralization. It is suggested that most of the change in the aBMD induced by antiresorptive therapies results from the increase in the MDMB.

The effects of antiresorptive therapy on cortical bone are limited, but suggestive of little impact on size albeit decreased porosity. The relatively modest changes in aBMD despite dramatic decreases in antifracture efficacy observed in antiresorptive trials may be at least partially a consequence of reduced bone remodeling which leads to an increase in bone mass and to a decrease in the number of trabecular stress-risers.

On the other hand, TPT has been shown to increase trabecular thickness and bone turnover; however, because of its anabolic properties, it results in net bone gain, perhaps explaining some of its positive impact on fracture risk. Despite a dramatic increase in bone mass, the mineralization is actually decreased and the net result is a greater aBMD following therapy. Strontium ranelate, however, induces a falsely elevated $\mathrm{ABMD}$ as a result of its incorporation into the apatite.

Regarding microdamage, microcrack accumulation was observed in bone treated with BPs but its presence, induced by other drugs used in osteoporosis therapy, was not confirmed. In any case, therapeutic doses of BPs do not negatively impact on the accumulation of microcracks to a level that would increase fracture susceptibility in humans.

The future goal for fracture risk assessment is the development of a virtual biopsy to assess the material and structural properties of bone at clinically important sites simultaneously and noninvasively $(30)$.

Table 1. Factors that determine bone quality categorized by physical scale

\begin{tabular}{|c|c|}
\hline Scale & Bone characteristics \\
\hline$>10^{-3} \mathrm{~m}$ & $\begin{array}{l}\text { Bone size and bone shape } \\
\text { Bone density spatial distribution }\end{array}$ \\
\hline $10^{-6}-10^{-3} \mathrm{~m}$ & $\begin{array}{l}\text { Microarchitecture } \\
\text { Porosity } \\
\text { Cortical shell thickness } \\
\text { Lacunar number/morphology } \\
\text { Remodeling cavity number, size and distribution }\end{array}$ \\
\hline $10^{-9}-10-6 \mathrm{~m}$ & $\begin{array}{l}\text { Mineral and collagen distribution/alignment } \\
\text { Microdamage type, amount and distribution }\end{array}$ \\
\hline$<10^{-9} \mathrm{~m}$ & $\begin{array}{l}\text { Collagen structure and cross-linking } \\
\text { Mineral type and crystal aligment } \\
\text { Collagen-mineral interfaces }\end{array}$ \\
\hline
\end{tabular}

Adapted from Hernandez et al., 2006 (65).

Acknowledgments: we thank Dr. Bruno Ferraz de Souza for assisting the preparation of this manuscript.

Disclosure: no potential conflict of interest relevant to this article was reported.

\section{REFERENCES}

1. Christiansen C. Osteoporosis: diagnosis and management today and tomorrow. Bone. 1995;17(5 Suppl):513S-6S.

2. Kanis JA. Diagnosis of osteoporosis and assessment of fracture risk. Lancet. 2002;359(9321):1929-36.

3. Sornay-Rendu E, Munoz F, Garnero P, Duboeuf F, Delmas PD. Identification of osteopenic women at high risk of fracture: the OFELY study. J Bone Miner Res. 2005;20(10):1813-9.

4. Cummings SR, Karpf DB, Harris F, Genant HK, Ensrud K, LaCroix $A Z$, et al. Improvement in spine bone density and reduction in risk of vertebral fractures during treatment with antiresorptive drugs. Am J Med. 2002;112(4):281-9.

5. Chen P, Miller PD, Delmas PD, Misurski DA, Krege JH. Change in lumbar spine BMD and vertebral fracture risk reduction in teriparatide-treated postmenopausal women with osteoporosis. J Bone Miner Res. 2006;21(11):1785-90.

6. Chesnut $\mathrm{CH}, 3 \mathrm{rd}$, Rosen $\mathrm{CJ}$. Reconsidering the effects of antiresorptive therapies in reducing osteoporotic fracture. J Bone Miner Res. 2001;16(12):2163-72.

7. Watts NB. Bone quality: getting closer to a definition. J Bone Miner Res. 2002;17(7):1148-50. 
8. Felsenberg $\mathrm{D}$, Boonen $\mathrm{S}$. The bone quality framework: determinants of bone strength and their interrelationships, and implications for osteoporosis management. Clin Ther. 2005;27(1):1-11.

9. Link TM, Majumdar S, Augat $P$, Lin JC, Newitt D, Lu Y, et al. In vivo high resolution $\mathrm{MRI}$ of the calcaneus: differences in trabecular structure in osteoporosis patients. $\mathrm{J}$ Bone Miner Res. 1998;13(7):1175-82.

10. Chesnut $\mathrm{CH}, 3$ rd, Majumdar S, Newitt DC, Shields A, Van Pelt J, Laschansky $E$, et al. Effects of salmon calcitonin on trabecular microarchitecture as determined by magnetic resonance imaging: results from the QUEST study. J Bone Miner Res. 2005;20(9):1548-61.

11. Byrjalsen I, Leeming DJ, Qvist P, Christiansen C, Karsdal MA. Bone turnover and bone collagen maturation in osteoporosis: effects of antiresorptive therapies. Osteoporos Int. 2008;19(3):339-48.

12. Laurent Benhamou C. Bone ultrastructure: evolution during osteoporosis and aging. Osteoporos Int. 2009;20(6):1085-7.

13. Leeming DJ, Henriksen K, Byrjalsen I, Qvist P, Madsen SH, Garnero $\mathrm{P}$, et al. Is bone quality associated with collagen age? Osteoporos Int. 2009;20(9):1461-70.

14. Riggs BL, O'Fallon WM, Lane A, Hodgson SF, Wahner HW, Muhs $\mathrm{J}$, et al. Clinical trial of fluoride therapy in postmenopausal osteoporotic women: extended observations and additional analysis. J Bone Miner Res. 1994;9(2):265-75.

15. Ruppel ME, Burr DB, Miller LM. Chemical makeup of microdamaged bone differs from undamaged bone. Bone. 2006;39(2):318-24.

16. Burr DB, Forwood MR, Fyhrie DP, Martin RB, Schaffler MB, Turner $\mathrm{CH}$. Bone microdamage and skeletal fragility in osteoporotic and stress fractures. J Bone Miner Res. 1997;12(1):6-15.

17. Chapurlat RD, Delmas PD. Bone microdamage: a clinical perspective. Osteoporos Int. 2009;20(8):1299-308.

18. Sunyecz J. Optimizing dosing frequencies for bisphosphonates in the management of postmenopausal osteoporosis: patient considerations. Clin Interv Aging. 2008;3(4):611-27.

19. Boivin GY, Chavassieux PM, Santora AC, Yates J, Meunier PJ. Alendronate increases bone strength by increasing the mean degree of mineralization of bone tissue in osteoporotic women. Bone. 2000;27(5):687-94.

20. Borah B, Dufresne TE, Ritman EL, Jorgensen SM, Liu S, Chmielewski PA, et al. Long-term risedronate treatment normalizes mineralization and continues to preserve trabecular architecture: sequential triple biopsy studies with micro-computed tomography. Bone. 2006;39(2):345-52.

21. Zoehrer R, Roschger $P$, Paschalis EP, Hofstaetter JG, Durchschlag $E$, Fratzl $P$, et al. Effects of 3- and 5-year treatment with risedronate on bone mineralization density distribution in triple biopsies of the iliac crest in postmenopausal women. J Bone Miner Res. 2006;21(7):1106-12.

22. Recker RR, Delmas PD, Halse J, Reid IR, Boonen S, Garcia-Hernandez PA, et al. Effects of intravenous zoledronic acid once yearly on bone remodeling and bone structure. J Bone Miner Res. 2008;23(1):6-16.

23. Ebeling PR, Burr DB. Positive effects of intravenous zoledronic acid on bone remodeling and structure: are different effects on osteoblast activity to other oral bisphosphonates responsible? J Bone Miner Res. 2008;23(1):2-5.

24. Mashiba T, Turner $\mathrm{CH}$, Hirano T, Forwood MR, Johnston CC, Burr DB. Effects of suppressed bone turnover by bisphosphonates on microdamage accumulation and biomechanical properties in clinically relevant skeletal sites in beagles. Bone. 2001;28(5):524-31.

25. Allen MR, Iwata K, Sato M, Burr DB. Raloxifene enhances vertebral mechanical properties independent of bone density. Bone. 2006;39(5):1130-5.
26. Allen MR, Burr DB. Mineralization, microdamage, and matrix: how bisphosphonates influence material properties of bone. Bonekey Osteovision. 2007;4(2):49-60.

27. Saito M, Mori S, Mashiba T, Komatsubara S, Marumo K. Collagen maturity, glycation induced-pentosidine, and mineralization are increased following 3-year treatment with incadronate in dogs. Osteoporos Int. 2008;19(9):1343-54.

28. Allen MR, Gineyts E, Leeming DJ, Burr DB, Delmas PD. Bisphosphonates alter trabecular bone collagen cross-linking and isomerization in beagle dog vertebra. Osteoporos Int. 2008;19(3):329-37.

29. Saito M, Fujii K, Soshi S, Tanaka T. Reductions in degree of mineralization and enzymatic collagen cross-links and increases in glycation-induced pentosidine in the femoral neck cortex in cases of femoral neck fracture. Osteoporos Int. 2006;17(7):986-95.

30. Davison KS, Siminoski K, Adachi JD, Hanley DA, Goltzman D, Hodsman $A B$, et al. The effects of antifracture therapies on the components of bone strength: assessment of fracture risk today and in the future. Semin Arthritis Rheum. 2006;36(1):10-21.

31. Recker RR, Ste-Marie LG, Langdahl B, Czerwinski E, Bonvoisin B, Masanauskaite $D$, et al. Effects of intermittent intravenous ibandronate injections on bone quality and micro-architecture in women with postmenopausal osteoporosis: The DIVA study. Bone. 2009 Nov 10.

32. Chen P, Miller PD, Recker R, Resch H, Rana A, Pavo I, et al. Increases in BMD correlate with improvements in bone microarchitecture with teriparatide treatment in postmenopausal women with osteoporosis. J Bone Miner Res. 2007;22(8):1173-80.

33. Arlot M, Meunier PJ, Boivin G, Haddock L, Tamayo J, Correa-Rotter $R$, et al. Differential effects of teriparatide and alendronate on bone remodeling in postmenopausal women assessed by histomorphometric parameters. J Bone Miner Res. 2005;20(7):1244-53.

34. Ma YL, Zeng Q, Donley DW, Ste-Marie LG, Gallagher JC, Dalsky $\mathrm{GP}$, et al. Teriparatide increases bone formation in modeling and remodeling osteons and enhances IGF-II immunoreactivity in postmenopausal women with osteoporosis. J Bone Miner Res. 2006;21(6):855-64.

35. Jiang Y, Zhao JJ, Mitlak BH, Wang O, Genant HK, Eriksen EF. Recombinant human parathyroid hormone (1-34) [teriparatide] improves both cortical and cancellous bone structure. J Bone Miner Res. 2003;18(11):1932-41.

36. Parfitt AM. Parathyroid hormone and periosteal bone expansion. J Bone Miner Res. 2002;17(10):1741-3.

37. Zanchetta JR, Bogado CE, Ferretti JL, Wang O, Wilson MG, Sato $M$, et al. Effects of teriparatide [recombinant human parathyroid hormone (1-34)] on cortical bone in postmenopausal women with osteoporosis. J Bone Miner Res. 2003;18(3):539-43.

38. Burr DB, Hirano T, Turner CH, Hotchkiss C, Brommage R, Hock JM. Intermittently administered human parathyroid hormone(1-34) treatment increases intracortical bone turnover and porosity without reducing bone strength in the humerus of ovariectomized cynomolgus monkeys. J Bone Miner Res. 2001;16(1):157-65.

39. Sato $M$, Westmore $M, M a Y L$, Schmidt A, Zeng QQ, Glass EV, et al. Teriparatide [PTH(1-34)] strengthens the proximal femur of ovariectomized nonhuman primates despite increasing porosity. $\mathrm{J}$ Bone Miner Res. 2004;19(4):623-9.

40. Misof BM, Roschger P, Cosman F, Kurland ES, Tesch W, Messmer $P$, et al. Effects of intermittent parathyroid hormone administration on bone mineralization density in iliac crest biopsies from patients with osteoporosis: a paired study before and after treatment. J Clin Endocrinol Metab. 2003;88(3):1150-6.

41. Garnero P, Bauer DC, Mareau E, Bilezikian JP, Greenspan SL, Rosen $C$, et al. Effects of PTH and alendronate on type I collagen isomerization in postmenopausal women with osteoporosis: the PaTH study. J Bone Miner Res. 2008;23(9):1442-8. 
42. Paschalis EP, Glass EV, Donley DW, Eriksen EF. Bone mineral and collagen quality in iliac crest biopsies of patients given teriparatide: new results from the fracture prevention trial. J Clin Endocrinol Metab. 2005;90(8):4644-9.

43. Dobnig H, Stepan JJ, Burr DB, Li J, Michalska D, Sipos A, et al. Teriparatide reduces bone microdamage accumulation in postmenopausal women previously treated with alendronate. J Bone Miner Res. 2009 May 19.

44. Reginster JY, Bruyere O, Sawicki A, Roces-Varela A, Fardellone $P$, Roberts $A$, et al. Long-term treatment of postmenopausal osteoporosis with strontium ranelate: results at 8 years. Bone. 2009;45(6):1059-64.

45. Cortet B. Strontium ranelate: new perspectives for the management of osteoporosis. Rheumatology (Oxf). 2009;48 Suppl 4:iv1-2.

46. Bruyere O, Roux C, Detilleux J, Slosman DO, Spector TD, Fardellone $\mathrm{P}$, et al. Relationship between bone mineral density changes and fracture risk reduction in patients treated with strontium ranelate. J Clin Endocrinol Metab. 2007;92(8):3076-81.

47. Ammann P, Shen V, Robin B, Mauras Y, Bonjour JP, Rizzoli R. Strontium ranelate improves bone resistance by increasing bone mass and improving architecture in intact female rats. J Bone Miner Res. 2004;19(12):2012-20.

48. Ammann P. Strontium ranelate: a physiological approach for an improved bone quality. Bone. 2006;38(2 Suppl 1):15-8.

49. Arlot ME, JiangY, Genant HK, Zhao J, Burt-Pichat B, Roux JP, et al. Histomorphometric and microCT analysis of bone biopsies from postmenopausal osteoporotic women treated with strontium ranelate. J Bone Miner Res. 2008;23(2):215-22.

50. Nelson HD, Humphrey LL, Nygren P, Teutsch SM, Allan JD. Postmenopausal hormone replacement therapy: scientific review. JAMA. 2002;288(7):872-81.

51. Khastgir G, Studd J, Holland N, Alaghband-Zadeh J, Fox S, Chow J. Anabolic effect of estrogen replacement on bone in postmenopausal women with osteoporosis: histomorphometric evidence in a longitudinal study. J Clin Endocrinol Metab. 2001;86(1):289-95.

52. Vedi S, Bell KL, Loveridge N, Garrahan N, Purdie DW, Compston $J E$. The effects of hormone replacement therapy on cortical bone in postmenopausal women. A histomorphometric study. Bone. 2003;33(3):330-4.

53. Paschalis EP, Boskey AL, Kassem M, Eriksen EF. Effect of hormone replacement therapy on bone quality in early postmenopausal women. J Bone Miner Res. 2003;18(6):955-9.
54. Ettinger B, Black DM, Mitlak BH, Knickerbocker RK, Nickelsen T, Genant HK, et al. Reduction of vertebral fracture risk in postmenopausal women with osteoporosis treated with raloxifene: results from a 3-year randomized clinical trial. Multiple Outcomes of Raloxifene Evaluation (MORE) Investigators. JAMA. 1999;282(7):637-45.

55. Sarkar S, Mitlak BH, Wong M, Stock JL, Black DM, Harper KD. Relationships between bone mineral density and incident vertebral fracture risk with raloxifene therapy. J Bone Miner Res. 2002;17(1):1-10.

56. Weinstein RS, Parfitt AM, Marcus R, Greenwald M, Crans G, Muchmore DB. Effects of raloxifene, hormone replacement therapy, and placebo on bone turnover in postmenopausal women. Osteoporos Int. 2003;14(10):814-22.

57. Brennan TC, Rizzoli R, Ammann P. Selective modification of bone quality by PTH, pamidronate, or raloxifene. J Bone Miner Res. 2009;24(5):800-8.

58. Boivin G, Lips P, Ott SM, Harper KD, Sarkar S, Pinette KV, et al. Contribution of raloxifene and calcium and vitamin D3 supplementation to the increase of the degree of mineralization of bone in postmenopausal women. J Clin Endocrinol Metab. 2003;88(9):4199-205.

59. Johnell O, Scheele WH, Lu Y, Reginster JY, Need AG, Seeman E. Additive effects of raloxifene and alendronate on bone density and biochemical markers of bone remodeling in postmenopausal women with osteoporosis. J Clin Endocrinol Metab. 2002;87(3):985-92.

60. Cranney A, Tugwell P, Zytaruk N, Robinson V, Weaver B, Shea B, et al. Meta-analyses of therapies for postmenopausal osteoporosis. VI. Meta-analysis of calcitonin for the treatment of postmenopausal osteoporosis. Endocr Rev. 2002;23(4):540-51.

61. Chesnut $\mathrm{CH}$, 3rd, Silverman S, Andriano K, Genant H, Gimona A, Harris $S$, et al. A randomized trial of nasal spray salmon calcitonin in postmenopausal women with established osteoporosis: the prevent recurrence of osteoporotic fractures study. PROOF Study Group. Am J Med. 2000;109(4):267-76.

62. Licata AA. Clinical perspectives on bone quality in osteoporosis: effects of drug therapy. Drugs Aging. 2007;24(7):529-35.

63. Bouxsein ML. Determinants of skeletal fragility. Best Pract Res Clin Rheumatol. 2005;19(6):897-911.

64. Seeman E. Bone quality: the material and structural basis of bone strength. J Bone Miner Metab. 2008;26(1):1-8.

65. Hernandez CJ, Keaveny TM. A biomechanical perspective on bone quality. Bone. 2006;39(6):1173-81. 